Article

\title{
Two-Phase Linear Hybrid Reluctance Actuator with Low Detent Force
}

\author{
Jordi Garcia-Amorós ${ }^{1, * \mathbb{D}}$, Marc Marín-Genescà ${ }^{2} \mathbb{D}$, Pere Andrada ${ }^{3} \mathbb{D}$ and Eusebi Martínez-Piera ${ }^{3}$ \\ 1 Electrical and Electronic Engineering Departament, Universitat Rovira i Virgili, Av. Països Catalans 26, \\ 43007 Tarragona, Spain \\ 2 Mechanical Engineering Department, Universitat Rovira i Virgili, Av. Països Catalans 26, \\ 43007 Tarragona, Spain; marc.marin@urv.cat \\ 3 GAECE, Electric Engineering Department, Universitat Politècnica de Catalunya, BARCELONATECH, \\ EPSEVG Av. Victor Balaguer 1, 08800 Vilanova i la Geltrú, Spain; pere.andrada@upc.edu (P.A.); \\ mtzpiera@ee.upc.edu (E.M.-P.) \\ * Correspondence: jordi.garcia-amoros@urv.cat
}

Received: 18 August 2020; Accepted: 1 October 2020; Published: 3 October 2020

\begin{abstract}
In this paper, a novel two-phase linear hybrid reluctance actuator with the double-sided segmented stator, made of laminated $U$ cores, and an interior mover with permanent magnets is proposed. The permanent magnets are disposed of in a way that increases the thrust force of a double-sided linear switched reluctance actuator of the same size. To achieve this objective, each phase of the actuator is powered by a single H-bridge inverter. To reduce the detent force, the upper and the lower stator were shifted. Finite element analysis was used to demonstrate that the proposed actuator has a high force density with low detent force. In addition, a comparative study between the proposed linear hybrid reluctance actuator, linear switched reluctance, and linear permanent magnet actuators of the same size was performed. Finally, experimental tests carried out in a prototype confirmed the goals of the proposed actuator.
\end{abstract}

Keywords: linear electric actuators; linear switched reluctance actuators; permanent magnets; linear hybrid reluctance actuators; machine design; finite element analysis; detent force reduction

\section{Introduction}

Nowadays, many applications that use hydraulic or pneumatic drives or even electric drives combined with mechanical transmission systems are being substituted by linear electric actuators in industrial and aerospace applications. These actuators convert electric energy directly into a linear controlled movement with low cost and simple control. They are constituted of a fixed part or stator (primary) and a moving part or mover (secondary), both parts can contain coils, permanent magnets (PM) or bars. There are different kinds of linear electric actuators but linear switched reluctance motors (LSRM) are an attractive option due to their simple construction, robustness, and good fault capability despite their low force/mass ratio [1,2]. This disadvantage can be relieved by inserting permanent magnets (PM) in its magnetic structure, giving rise to the linear hybrid reluctance actuators. In some of these actuators, due to the disposition of the permanent magnets, the detent force is negligible [3]. Unfortunately, in most of these types of machines when the phases are not energized a detent force appears because of the interaction between the permanent magnets and the poles or teeth in which the windings are disposed of. Different techniques have been proposed for the reduction in detent force, the most usual are aside PM skewing and PM length/width adjustment [4,5], an asymmetric arrangement of PM, use of semi-closed slots [6], and utilization of auxiliary teeth or teeth notching [7]. Some other techniques use specific control strategies [8], in some cases, a combination of control and 
structural design (e.g., skewing PM, Halbach array) are employed $[9,10]$, and others are based on the shift of the permanent magnets, poles and slots, the slots or poles and the distance between the magnet segments of each pole [11-14].

During the work cycle (ascent or horizontal for linear machine), the propulsion force and direction of motion are in the same direction, and during descent, the propulsion force is acting in the direction opposite to that of the motion $[15,16]$. Propulsion force is a key concept for this type of machine, this defines the application in each type of machine configuration, and therefore defines a profile of force $\left(F_{X}\right)$ and displacement $(x)$ with peaks and minimums of propulsion force, which are necessary to adapt to the different applications [16]. Regarding the detent force importance, the main constraint of the slotted iron core type in magnet linear motors is the detent force that is caused by the interaction between the permanent magnet (PM) and the slotted iron core. This detent force will generate the pulsations of the propulsion force, and it will deteriorate the smoothness of motion drive, one of the main goals of the design of this type of electrical machine is to minimize this detent force. In general, the amplitude of the detent force is dependent on some major factors, such as pole-arc to a pole-pitch ratio of a magnet, air-gap length, slot opening length, skew of either stator teeth or magnet poles, and other key design factors $[17,18]$.

Reluctance machines present good environmental behavior due to their high efficiency and inherent ease of assembly and dismantling [19]. For these reasons, among others, several studies have focused on new magnetic structures $[20,21]$ in order to enhance their force performance [22] and increase force density by adding permanent magnets, some examples of electrical machines using permanent magnets have been developed recently in many research works [22-27]. As an example, linear switched reluctance motors (LSRM) and linear permanent magnet synchronous motors (LPMSMs) have been proposed for propelling a ropeless elevator [28], for an automotive suspension system [29], and for a linear generator in direct drive wave-power converter [30]. Despite their advantages, the permanent magnets linear (PML) motors exhibit some drawbacks: one of them is the presence of a cogging force, which can introduce a disturbance in positioning precision. The cogging force, in PML motors, is caused by two phenomena. The first one arises from the interaction between the PMs and the finite length of the armature core and is often called "end-effect". It can be minimized by adopting a suitable stator length [31] or modifying the extremity shape of the shorter part [32]. On the other hand, the U-core or U-channel air-core permanent magnet linear synchronous motors are widely applied in direct-drive linear motion servo systems, as they could offer significant advantages in terms of high efficiency, high positioning accuracy, rapid dynamic response, simple structure, and long service lifetime [33-36].

In this paper, a two-phase double-sided segmented stator, using laminated U cores, with an interior PM mover is proposed. Its main goal is to have high propulsion or thrust force and a low detente force.

The former concept-design of this two-phase linear hybrid reluctance motor comes from the optimized LSRM presented in [1], from which mover and stator dimensions are kept. That magnetic structure was hybridized by inserting Neodymium Iron Boron NdFeB magnets and was analyzed in [37].

The proposed two-phase actuator differs from the linear hybrid reluctance motor presented in [37] in the number of phases and in that the segmented stator is built with magnetically and mechanically decoupled $U$ cores. This fact allows the relative displacement of the lower stator to respect the upper stator for reducing the detent force

After this introduction, the paper is organized as follows. In Section 2, a description of the proposed actuator is provided. The simulation of the actuator is performed with a $2 \mathrm{D}$ finite element analysis in Section 3. The reduction in the detent force is addressed in Section 4. A comparative study regarding switched reluctance and linear permanent actuators of the same size is performed in Section 5 . The verification results obtained by $3 \mathrm{D}$ finite element analysis and experimental tests are shown in Section 6. Finally, in Section 7, conclusions from this research are drawn. 


\section{Description of the Proposed Actuator}

In order to enhance the propulsion force of a conventional two-phase LSRM, a new two-phase double-sided linear hybrid reluctance actuator (PM-LHRM) is proposed. Figure 1 is a drawing of the PM-LHRM arrangement, wherein light grey shows the two symmetrical primary structures that contains the two phases, in blue and red, respectively, for the two phases $\mathrm{B}$ and $\mathrm{C}$, whose magnetic circuit is made of two $U$ laminated cores per phase. The secondary, depicted in grey, has disposed of the permanent magnets (NdFeB-N32) (in black/white) between their poles with the direction of magnetization shown in Figure 1 (S-N-S-N-S ... in both sides). Each phase is energized through an $\mathrm{H}$-bridge inverter that allows switching the phase current to a positive value $+\mathrm{I}$ to a negative value $-\mathrm{I}$ in the period of conduction of the corresponding phase. The goal is to double the total average force of a linear switched reluctance actuator of the same geometry. The actuator is intended for short-time duty cycle (S2) applications with an average total thrust of $100 \mathrm{~N}$ at a speed of $0.15 \mathrm{~m} / \mathrm{s}$, which not require a very precise positioning such as automatic door opener systems.

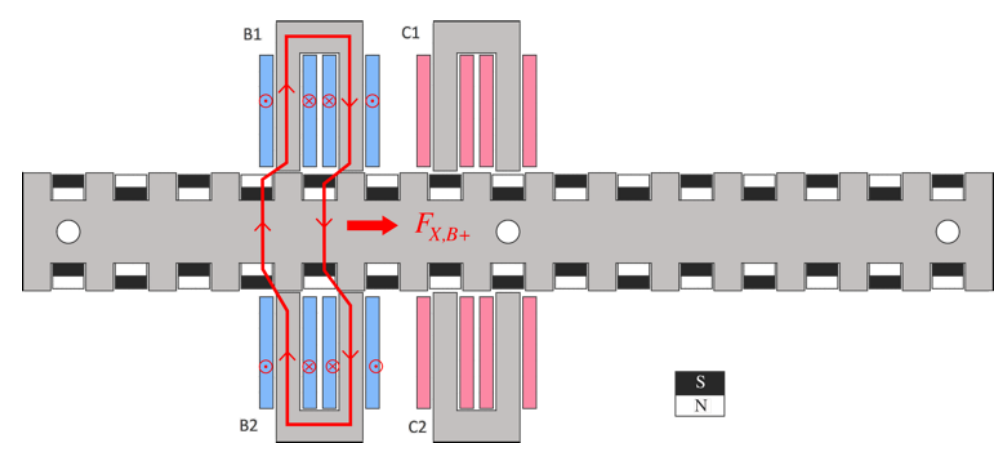

Figure 1. View of the proposed two-phase double-sided linear hybrid reluctance actuator (PM-LHRM) and operation principle when exciting phase $\mathrm{B}+$ at $x=0 \mathrm{~mm}$.

The operating principle is shown in Figure 1, which sketches a field line when exciting phase $\mathrm{B}$ with a positive current, called $\mathrm{B}+$, and the resulting propulsion force $\left(F_{X, B+}\right)$ in the right direction (positive). Without PMs in the mover, the structure is a conventional LSRM, in which feeding the same phase $\mathrm{B}+$ the propulsion force is zero at $x=0 \mathrm{~mm}$, and the same would happen by feeding phase $\mathrm{C}$. The existence of these zero-force positions disables the two-phase LSRM as a propulsion actuator.

In order to assess the PM-LHRM, it will be compared with a pure reluctance motor, demoted by LSRM (see Figure 2a), and with a permanent magnet linear motor without iron poles in the mover, denoted by PM-LM (see Figure 2b). The LSRM and PM-LM actuators have the same stator structure of Figure 1, but their respective movers are different as shown in Figure 2.

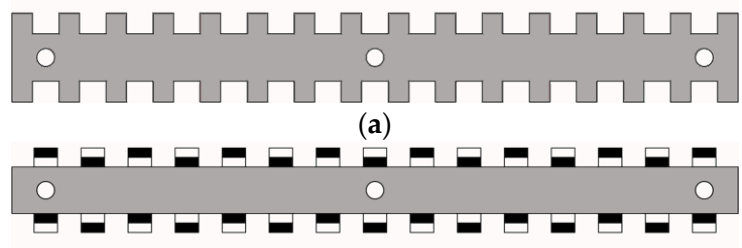

(b)

Figure 2. Mover structures (a) linear switched reluctance motor (LSRM) (b) PM-LM.

Some relevant details about the design of the proposed machine are given in the Appendix A.

\section{Simulation of the Actuator}

The PM-LHRM, LSRM, and PM-LM actuators were simulated using 2D finite element analysis [38] and Matlab, for a current density of $10 \mathrm{~A} / \mathrm{mm}^{2}$. This current density value is chosen because the 
actuator is conceived for short intermittent duty cycles. It is important to point out that there is only one flux-path per phase, and the phases are magnetically uncoupled, that is, the flux created by coil phase B does not link coil phase C. The simulation model has more than $185 \mathrm{k}$ elements and nearly $93 \mathrm{k}$ nodes, and a simulation solver precision of 10 nano. Figure 3a shows the comparison between the force profiles of the three structures, in which it can be seen a prominent force peak $(>150 \mathrm{~N})$ for the PM-LHRM, which doubles the force peak $\left(F_{\text {peak }}\right)$ of the LSRM. Moreover, the force becomes anti-symmetric for the PM-LHRM when the phase-current is inverted, that means zero-force positions can be overlapped when phases are fed with the appropriate sequence (e.g., B+ C+ B- C-), as can be seen in Figure $3 b$. Therefore, adding the PMs to the two-phase LSRM magnetic circuit allows the elimination of zero-force positions, which position this PM-LHRM configuration as a good solution for high-density thrust actuators. The relevant values shown in Figure 3 are $F_{\text {peak }}=162.8 \mathrm{~N}$ for the PM-LHRM, $F_{\text {peak }}=$ $128.8 \mathrm{~N}$ for PM-LM, $F_{\text {peak }}=75.8 \mathrm{~N}$ for LSRM, and the average force values $F_{\text {ave }}=91.4 \mathrm{~N}, F_{\text {ave }}=78.1 \mathrm{~N}$, $F_{\text {ave }}=46.6 \mathrm{~N}$, respectively, being the average force values computed over a semi-period.

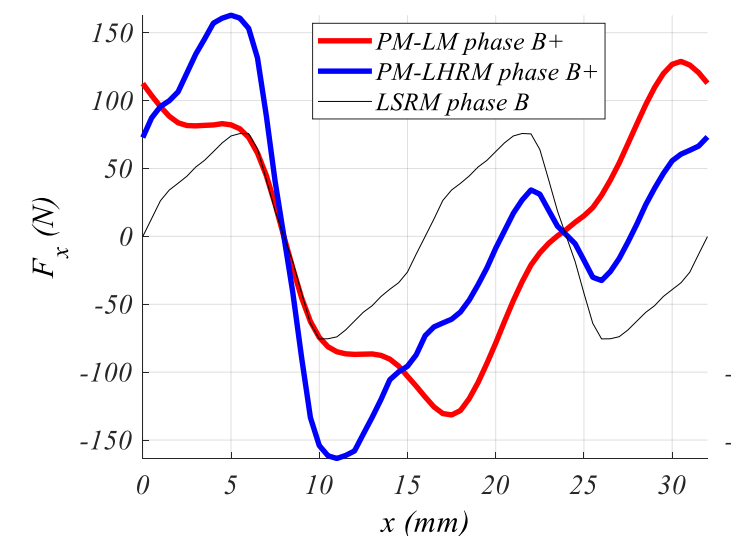

(a)

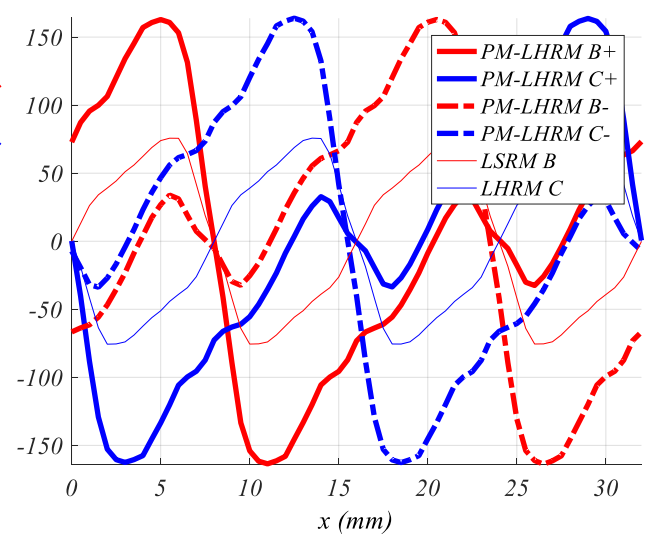

(b)

Figure 3. Propulsion force $(\mathrm{N})$ vs. position $(\mathrm{mm})$ simulation results at $\mathrm{J}=10 \mathrm{~A} / \mathrm{mm}^{2}$ and shift $=0 \mathrm{~mm}$. (a) Comparison of the 3 structures. (b) Comparison for the PM-LHRM and LSRM structure feeding phases $\mathrm{B}+, \mathrm{C}+, \mathrm{B}-, \mathrm{C}-$.

The detent force that appears when currents are zero, due to the presence of PMs, is represented in Figure 4. The detent force values are $28.2 \mathrm{~N}$ of peak, (17.3\% of peak force) and a root mean square (rms) value $18.9 \mathrm{~N}$-rms for the PM-LHRM structure, and $22.9 \mathrm{~N}$ of peak (17.8\% of peak force) and $14.6 \mathrm{~N}$-rms for PM-LM. These values are far from negligible and therefore they are a significant drawback, despite the better performance of PM-LHRM and PM-LM in respect to the LSRM.

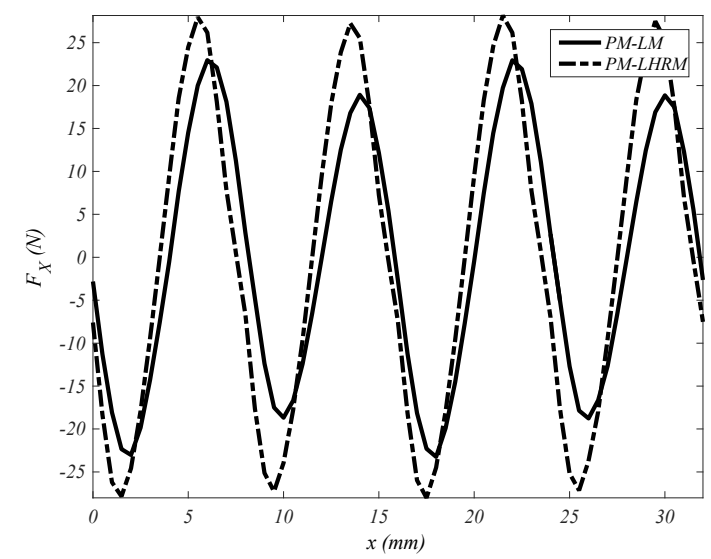

Figure 4. Detent force or cogging force for PM-LM and PM-LHRM at shift $=0 \mathrm{~mm}$. 


\section{Reduction in Detent Force}

The PM linear motors and by extension the hybrid magnetic structures exhibit the so-called detent force, which means the existence of a threshold force under which the motor cannot operate. This force is due to the PM flux lines that sew stator and rotor at given positions due to the slotted structures, called "slotting effect". This causes error in positioning, vibrations, and noise. Reference [12] classifies linear motors according to $X$ configuration, where the secondary is longer than primary, and $Y$ configuration, where secondary is shorter than primary. Both configurations suffer the "slotting effect", additionally $X$ configuration also has the "end-effect", which has less relevance than the "slotting effect", as shown in Section 6.

After considering the different alternatives exposed in Section 1 for the reduction in detent force, the option based on the technique of pole shifting [12] was selected because it was the easiest to implement given the modular arrangement of the proposed actuator built with independent $\mathrm{U}$ cores. This was implemented maintaining the $\mathrm{U}$ cores of the upper stator- $\mathrm{B} 1$ and $\mathrm{C} 1-\mathrm{in}$ the same position (see Figure 1), and displacing the $\mathrm{U}$ cores of the lower stator-B2 and $\mathrm{C} 2$-a certain distance, called shift, into the right direction.

To analytically approach the analysis, several methodologies are presented in $[9,10,14]$. In this case, a simplified magnetic equivalent circuit based on Figure 1 is proposed (see Figure 5). In this approach, the iron reluctances are neglected as well as the leakage fluxes. In Figure 5, FI stands for the phase-coil magneto-motive force ( $m m f$ ) and FM for the magnet's $m m f$, being $F_{M}=H_{M} \cdot l_{m}$. A sinusoidal flux variation is also assumed in respect to position $x$, see Equations (1) and (2) for phase B and Equations (3) and (4) for phase C. It is also considered a variable accounting for the displacement $s$ between the upper and lower phase-stators to reduce the detent force. The numerical values for the variables $T_{s}, L_{W}$ and $C_{m}$ are given in the Appendix A Table A1.

$$
\begin{gathered}
\phi_{B 1}(x)=B_{r} \cdot L_{W} \cdot C_{m} \cdot \sin \left(\frac{\pi \cdot x}{T_{S}}\right) \\
\phi_{B 2}(x, s)=B_{r} \cdot L_{W} \cdot C_{m} \cdot \sin \left(\frac{\pi \cdot(x+s)}{T_{S}}\right) \\
\phi_{C 1}(x)=B_{r} \cdot L_{W} \cdot C_{m} \cdot \cos \left(\frac{\pi \cdot\left(x-\frac{T_{S}}{2}\right)}{T_{S}}\right) \\
\phi_{C 2}(x, s)=B_{r} \cdot L_{W} \cdot C_{m} \cdot \cos \left(\frac{\pi \cdot\left(x-\frac{T_{S}}{2}+s\right)}{T_{S}}\right)
\end{gathered}
$$

The reluctances, $\mathcal{R}(x, s)$, of each $U$ core, with regards to the value of $x$ and $s$ are obtained in the following Equations (5)-(8):

$$
\begin{gathered}
\mathcal{R}_{B 1}(x, s)=\left(\frac{\mathcal{R}_{\text {max }}-\mathcal{R}_{\text {min }}}{2}\right) \cdot\left(1-\cos \left(\frac{2 \cdot \pi \cdot x}{T_{S}}\right)\right)+\mathcal{R}_{\text {min }} \\
\mathcal{R}_{B 2}(x, s)=\left(\frac{\mathcal{R}_{\text {max }}-\mathcal{R}_{\text {min }}}{2}\right) \cdot\left(1-\cos \left(\frac{2 \cdot \pi \cdot(x+s)}{T_{S}}\right)\right)+\mathcal{R}_{\text {min }} \\
\mathcal{R}_{C 1}(x, s)=\left(\frac{\mathcal{R}_{\text {max }}-\mathcal{R}_{\text {min }}}{2}\right) \cdot\left(1-\cos \left(\frac{2 \cdot \pi \cdot\left(x-\frac{T_{S}}{2}\right)}{T_{S}}\right)\right)+\mathcal{R}_{\text {min }} \\
\mathcal{R}_{C 2}(x, s)=\left(\frac{\mathcal{R}_{\text {max }}-\mathcal{R}_{\text {min }}}{2}\right) \cdot\left(1-\cos \left(\frac{2 \cdot \pi \cdot\left(x-\frac{T_{S}}{2}+s\right)}{T_{S}}\right)\right)+\mathcal{R}_{\text {min }}
\end{gathered}
$$


The reluctance value $\mathcal{R}_{\max }$ corresponds to the unaligned position (see phase $\mathrm{C}$ in Figure 1 ) and $\mathcal{R}_{\min }$ to the aligned position (see phase B in Figure 1), these two reluctance values can be obtained analytically by computing and adding the permeance flux-tubes set obtained at the given positions. The detent force $\left(F_{d}\right)$ is then obtained by Equation (9).

$$
F_{d}(x, s)=\frac{1}{2} \cdot \sum_{i=1}^{2} \phi_{B i}(x, s)^{2} \cdot \frac{\delta \mathcal{R}_{B i}(x, s)}{\delta x}+\frac{1}{2} \cdot \sum_{i=1}^{2} \phi_{C i}(x, s)^{2} \cdot \frac{\delta \mathcal{R}_{C i}(x, s)}{\delta x}
$$

Thus, $F_{d}$ is minimized regarding the shift variable, $s$, reaching a minimum value of detent force at $s=4 \mathrm{~mm}$ for the given values.

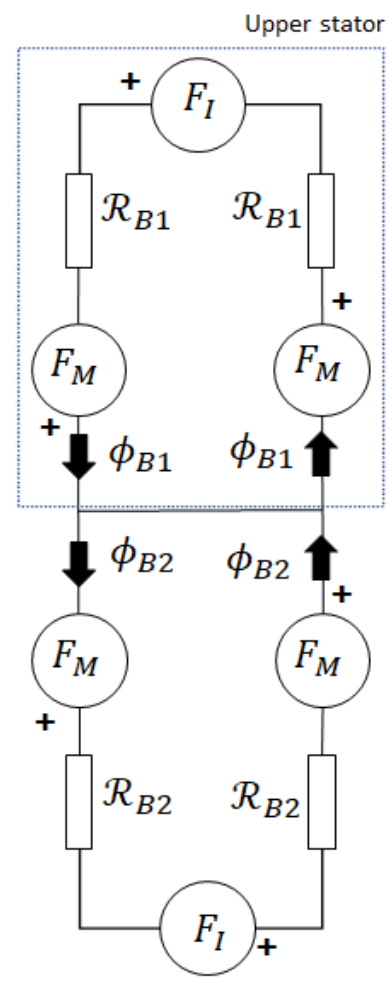

Figure 5. Simplified phase-B magnetic equivalent circuit for PM-LHRM.

In order to provide an expression involving the phase-current $(I)$ and the number of turns $(N)$, it can be obtained by applying the second Kirchoff law to either of the loops (see Figure 5), resulting:

$$
F_{I}=2 \cdot R_{B 1} \cdot \phi_{B 1}+2 \cdot F_{M} \rightarrow I=\frac{2}{N} \cdot\left(R_{B 1} \cdot \phi_{B 1}+H_{M} \cdot l_{M}\right)
$$

The detent force is computed numerically using 2DFEM solver [39] by using Maxwell stress tensor and analytically by the set of Equations (1)-(9). Figure 6a shows the flux line distribution for a given position considering only phase B. Figure $6 \mathrm{~b}$ shows the flux distribution of the whole PM-LHRM for a given shift. To assess the goodness of the analytical approach, 2DFEM simulations are computed over a one phase (B), and it is considered the detent force of other phase (C) out of phase (i.e., $180^{\circ}$ ), regarding to phase $B$. The detent force comparison of each phase (phase $B$ in red and phase $C$ in blue) and the total force (in black) is depicted in Figure 7, for both analytical and 2DFEM results. As can be seen, both models match quite well at $s=4 \mathrm{~mm}$ when both, FEM and analytical, predict a minimum detent force. The differences with other shift values are due to the analytical model's accuracy, few flux tubes are considered, since the goal is not to present an accurate analytical model but rather to give an analytical vision on the effects of the shift displacement on the detent force. 


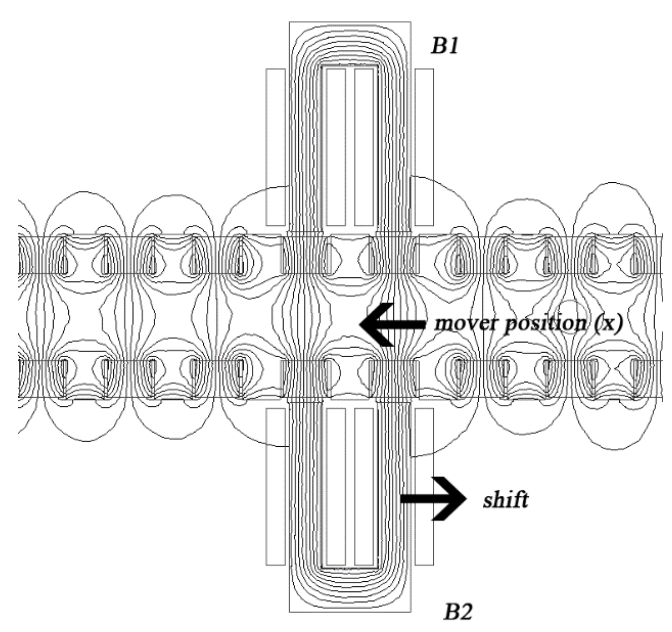

(a)

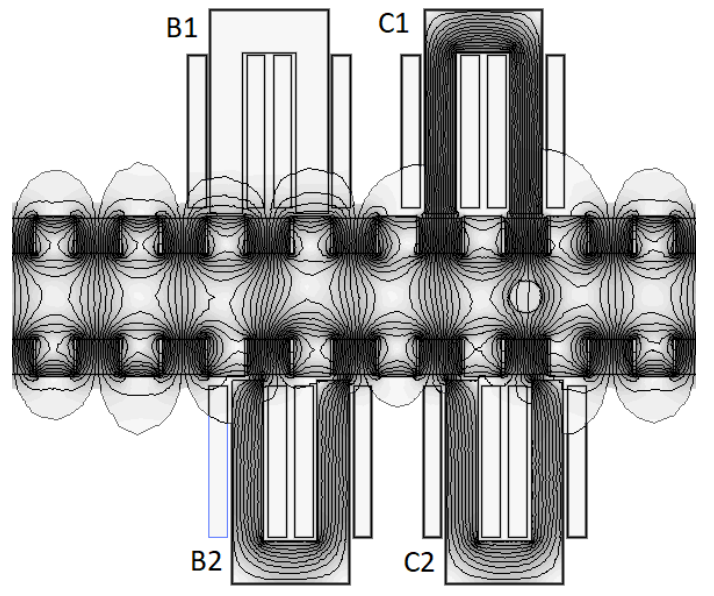

(b)

Figure 6. Field line distribution for PM-LHRM, $I_{B}=I_{C}=0$ and position $x=0 \mathrm{~mm}$. (a) B-phase $s=0$ mm. (b) whole PM-LHRM $s=4 \mathrm{~mm}$.

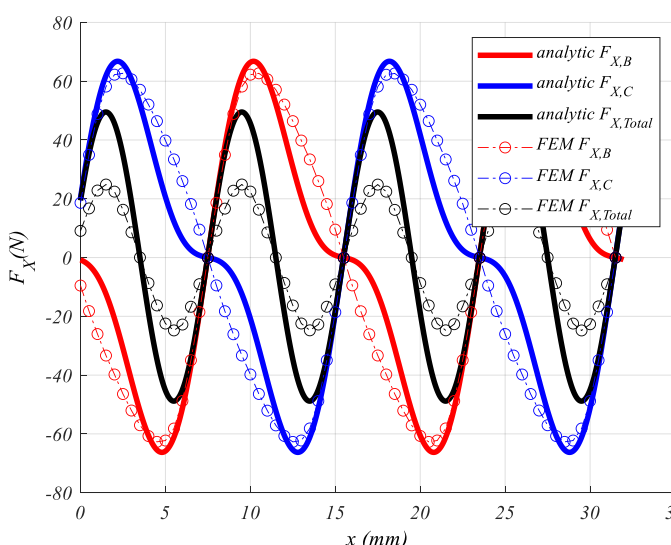

(a)

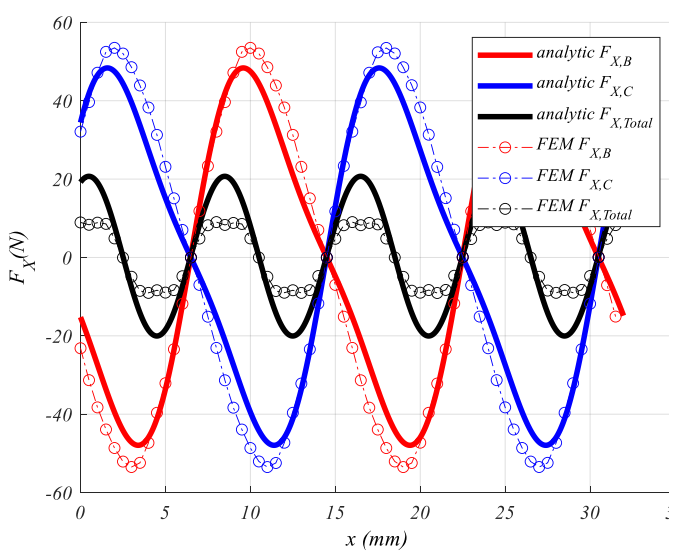

(c)

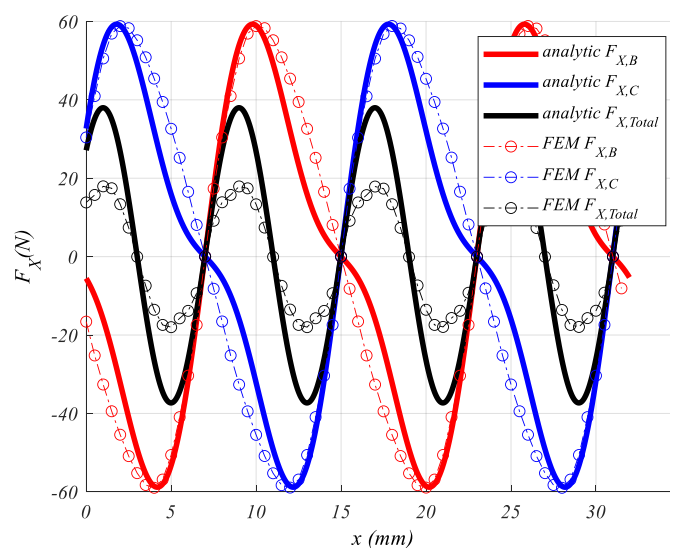

(b)

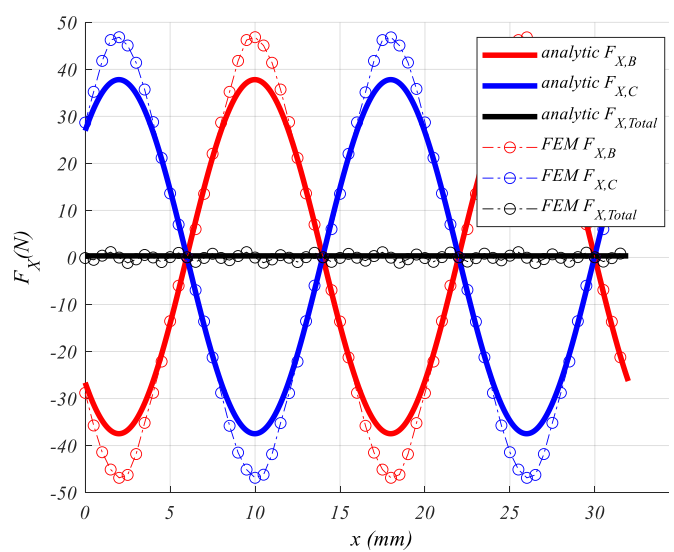

(d)

Figure 7. Detent force comparison results. (a) $s=1 \mathrm{~mm}$. (b) $s=2 \mathrm{~mm}$. (c) $s=3 \mathrm{~mm}$. (d) $s=4 \mathrm{~mm}$.

Figure 8 shows the simulation results of the detent force versus the shift for the whole PM-LHRM. The detent force results are minimal $s=4 \mathrm{~mm}$ as predicted by the analytical model, see Figure $7 \mathrm{~d}$. The detent force is computed for the whole PM-LHRM for ranges of shift (s) and mover positions $(x)$, which are: $s \in[0 \div 6 \mathrm{~mm}, \Delta s=1 \mathrm{~mm}]$ and $x \in[0 \div 32 \mathrm{~mm}, \Delta x=0.5 \mathrm{~mm}]$. The mover runs to the left, being the initial position, $x=0$, the position shown in Figure 1 . The distance covered by the mover, 
from $x=0 \mathrm{~mm}$ (see Figure 1) to the position in which stator $\mathrm{U}$ core B1 reaches the same relative position of $C 1$ at $x=0 \mathrm{~mm}$, is the period of detent force $(\tau)$, which for this actuator is $\tau=8 \mathrm{~mm}$. The results corroborate the analytical results obtained from (9), and the minimum detent force is obtained for a shift of $s=4 \mathrm{~mm}$ (see Figure 7). Repeating the simulations for the PM-LM structure also finds a minimum in the detent force at the same shift of $4 \mathrm{~mm}$.

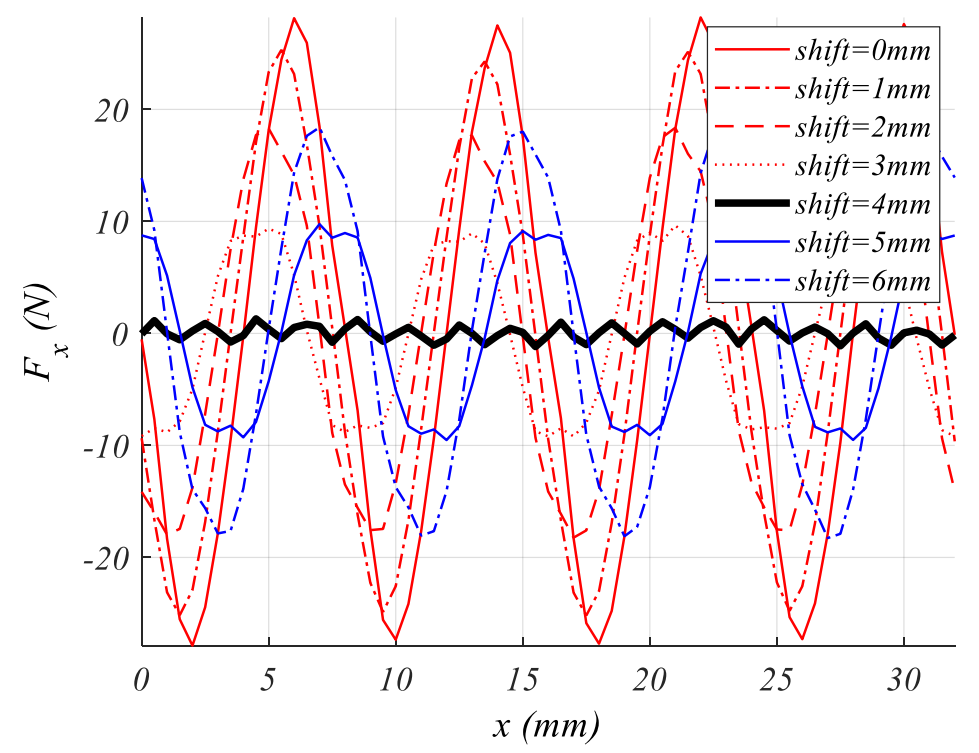

Figure 8. Detent force simulation results of the whole PM-LHRM.

\section{Comparative Study for Shifted Structures}

A comparison between the proposed PM-LHRM and the PM-LM simulation results is presented. Both motors are of the same size and have the same shift of $s=4 \mathrm{~mm}$. Figure 9a shows the detent force comparison of the two structures, in which the PM-LHRM present a significant lower detent force, meanwhile PM-LM has a wide cycle of the force of $16 \mathrm{~mm}$, with peaks points over $2.5 \mathrm{~N}$ and $-3 \mathrm{~N}$. Figure $9 \mathrm{~b}$ shows the propulsion force comparison results of the PM-LM and PM-LHRM structures, and also the LSRM. As can be seen, the force distributions obtained after shifting are significantly different in both PM motors. The peak forces are 130.4 N for PM-LHRM and 105.7 N for PM-LM, and the average forces are $60 \mathrm{~N}$ and $69 \mathrm{~N}$, respectively. From the simulation results presented in Figure 9a,b, PM-LHRM exhibits a lower detent force and a higher force peak in comparison with PM-LM. The LSRM shows the lowest propulsion force peak at $75 \mathrm{~N}$.

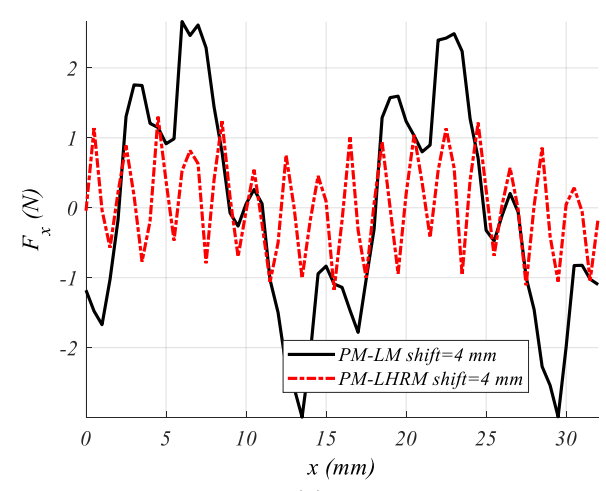

(a)

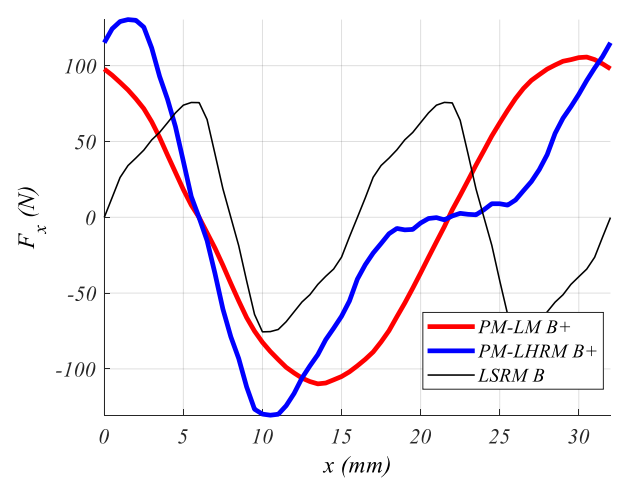

(b)

Figure 9. (a) Detent force comparison results at $s=4 \mathrm{~mm}$. (b) Phase force comparison results for a current density of $10 \mathrm{~A} / \mathrm{mm}^{2}$ and shift $=4 \mathrm{~mm}$. 
In order to assess the goodness of the proposed actuator versus its PM-LM counterpart, Figure 10a,b compare their propulsion force profiles, obtained by feeding the phases with a flat current waveform in switched reluctance mode, that is without overlapping phase currents. The phases are fed for obtaining a positive trust in the sequence $\mathrm{B}+\mathrm{C}-\mathrm{B}-\mathrm{C}+$. The total trust obtained is the enveloping of the force profiles in the red line.

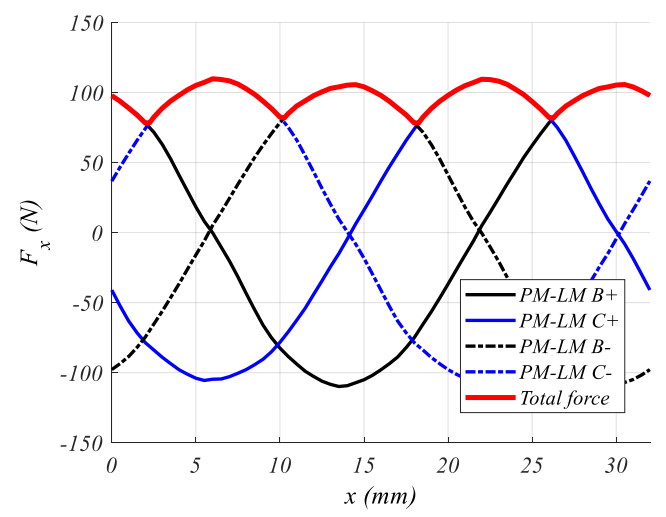

(a)

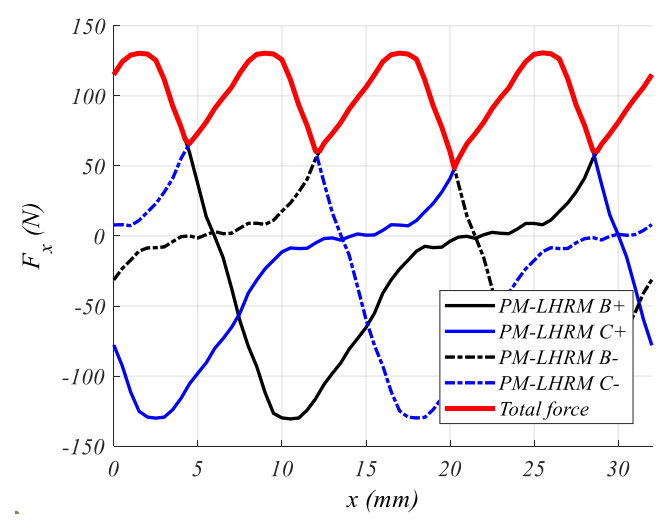

(b)

Figure 10. Phase force profiles and total force. (a) PM-LM at shift $=4 \mathrm{~mm}$. (b) PM-LHRM at shift $=4 \mathrm{~mm}$.

Figure 11 shows the comparison results of the total propulsion force of the three motors analyzed. The main values are summarized in Table 1, where to complete the study ripple factor is included (see Equation (11)), having been obtained through the following expression:

$$
F_{\text {ripple }}=\frac{F_{x, \max }-F_{x, \min }}{F_{x, \text { ave }}}
$$

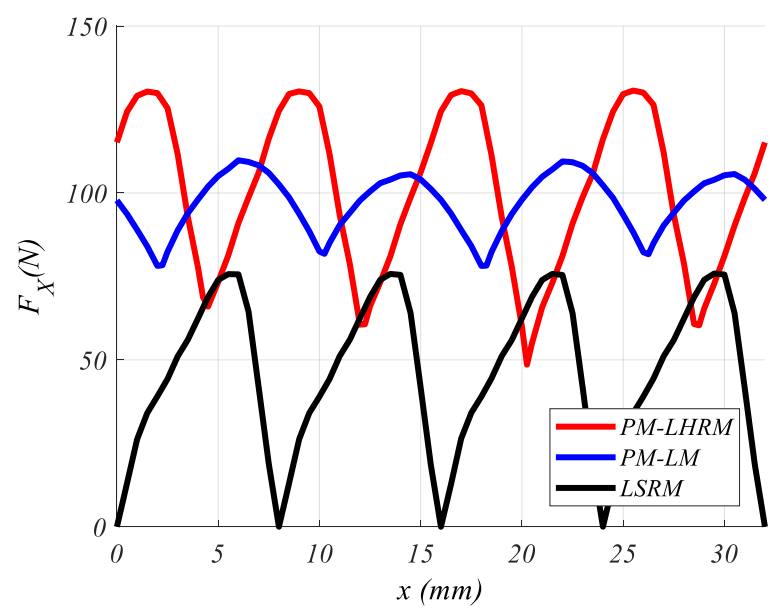

Figure 11. Total force simulation comparison results for the PM-LHRM and PM-LM, $s=4 \mathrm{~mm}$, and the LSRM at $10 \mathrm{~A} / \mathrm{mm}^{2}$.

Table 1. Main comparison simulation results from PM-LHRM, PM-LM, and LSRM.

\begin{tabular}{c|ccc|cc|cc}
\hline Structure & \multicolumn{3}{|c|}{ Total Force } & \multicolumn{2}{c|}{ Phase Force } & \multicolumn{2}{c}{ Detent Force } \\
\hline & $\boldsymbol{F}_{\text {peak }}$ & $\boldsymbol{F}_{\text {ave }}$ & $\boldsymbol{F}_{\text {ripple }}$ & $\boldsymbol{F}_{\text {peak }}$ & $\boldsymbol{F}_{\text {ave }}$ & $\boldsymbol{F}_{\text {peak }}$ & $\boldsymbol{F}_{\text {rms }}$ \\
\hline PM-LHRM & $130.7 \mathrm{~N}$ & $100.8 \mathrm{~N}$ & 0.81 & $130.7 \mathrm{~N}$ & $60 \mathrm{~N}$ & $1.3 \mathrm{~N}$ & $0.67 \mathrm{~N}$ \\
PM-LM & $109.8 \mathrm{~N}$ & $97.1 \mathrm{~N}$ & 0.33 & $105.7 \mathrm{~N}$ & $69.7 \mathrm{~N}$ & $2.66 \mathrm{~N}$ & $1.54 \mathrm{~N}$ \\
LSRM & $75.8 \mathrm{~N}$ & $46.2 \mathrm{~N}$ & 1.64 & $75.8 \mathrm{~N}$ & $46.5 \mathrm{~N}$ & 0 & 0 \\
\hline
\end{tabular}


In Figure 11, the work cycle of propulsion force shows a maximum for PM-LHRM, 130 N. For PM-LM shows a propulsion force with a displacement cycle of $8 \mathrm{~mm}$, with a lower maximum of force than the LHRM configuration $(109.8 \mathrm{~N})$, and minimum at $80 \mathrm{~N}$. Finally, LSRM shows the lowest propulsion force than the three configurations $(75.8 \mathrm{~N})$, and a displacement cycle of $8 \mathrm{~mm}$.

Table 1 collects the three parameters (peak force, average force, and ripple force) obtained from Figure 11, as well as the detent force peak and rms values obtained from Figure 9a. PM-LHRM shows the highest force peak, on the other hand, LSRM presents the lowest peak force, similarly, the $F_{\text {ave, }}$ presents the same trend as the $F_{\text {peak }}$ profiles. Detent forces present higher values for PM-LM (2.66 N) than PM-LHRM (1.3 N), but in very low percent values from $F_{\text {peak }}$ analyzed: $2.4 \%$ to 1\%, for PM-LM and PM-LHRM configurations, respectively.

\section{Verification Results}

A prototype of the proposed PM-LHRM actuator was built. In Figure 12a, a lamination of stator U-cores and the mover are shown. A picture of one of the U-core wounded is depicted in Figure $12 b$. The complete actuator can be seen in Figure 12c. The design specifications of the linear hybrid reluctance actuator are those given in the appendix.

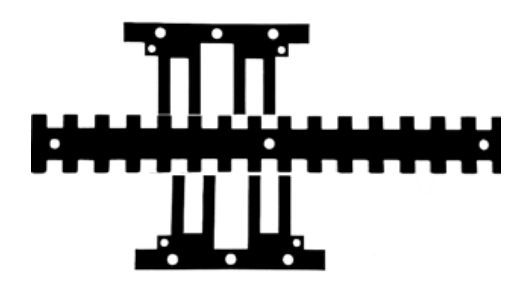

(a)

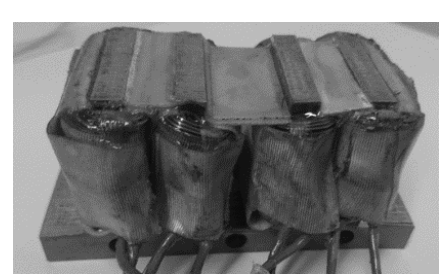

(b)

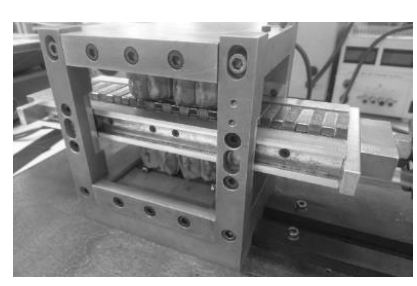

(c)

Figure 12. (a) Lamination of U-cores and mover. (b) Detail of one U-core with the stator coils. (c) View of the complete actuator.

The force measurements were done with a load cell, UTILCELL CR200. On the other hand, the magnetic field of all the permanent magnets were measured on the airgap surface with a gaussmeter model Tenmars TM-197 AC/DC, giving values ranging from \pm 0.47 to \pm 0.51 , giving an acceptable magnetic field symmetry.

To validate the FEM simulations, a 3D finite element analysis using Altair Flux ${ }^{\mathrm{TM}}$ [40] was performed to account for end-effects. An experimental test set-up (see Figure 12c) was used to obtain the curve force profile for each phase of the prototype (see Figures 13 and 14), feeding one current at a time: $\mathrm{I}_{\mathrm{B}+} \mathrm{I}_{\mathrm{B}-} \mathrm{I}_{\mathrm{C}+} \mathrm{I}_{\mathrm{C}-\text {, }}$ which for $J=10 \mathrm{~A} / \mathrm{mm}^{2}$ results from a value of $3.12 \mathrm{~A}$. These results are presented in Figures 13 and 14 along with the 2DFEM simulation results for each phase for a shift displacement of 0 and $4 \mathrm{~mm}$, respectively. The test system positioning consisted of a calibrated screw ( $1 \mathrm{~mm}$ per revolution) with a range of $28 \mathrm{~mm}$. From these figures, it can be seen a good agreement between simulation and experimental results. It is appreciated there is a slight shift of the experimental values in respect to the simulation, this is due to a positioning error of the screw system.

Figure 15 shows comparison results of the detent force for the two-shift considered. As can be seen, the experimental values of detent force for $s=4 \mathrm{~mm}$ reveals a significant difference between the 2DFEM results.

To shed some light on this discrepancy, a 3DFEM [41] simulation was performed. For $s=0 \mathrm{~mm}$, there is an acceptable concordance between the results 2DFEM, 3DFEM, and experimental (see Figure 16a). In contrast, for $s=4 \mathrm{~mm}$ the differences persist (see Figure 16a), which leads to the belief that end-effects are not relevant enough to produce such difference. 


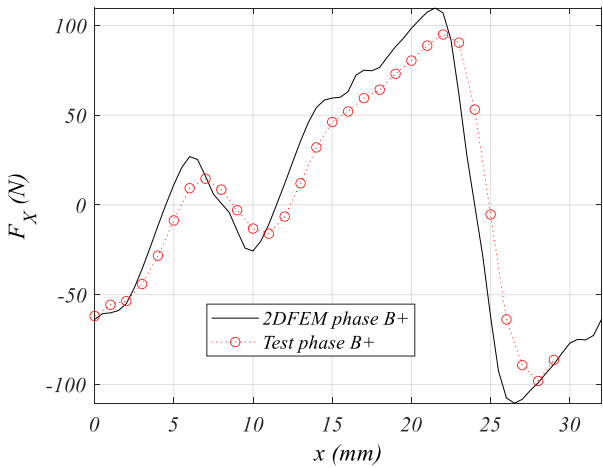

(a)

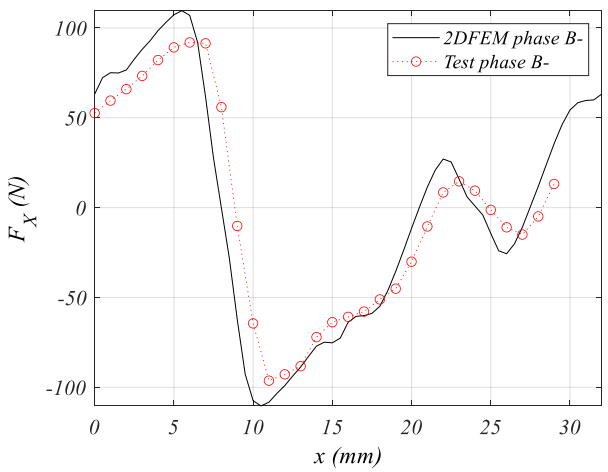

(c)

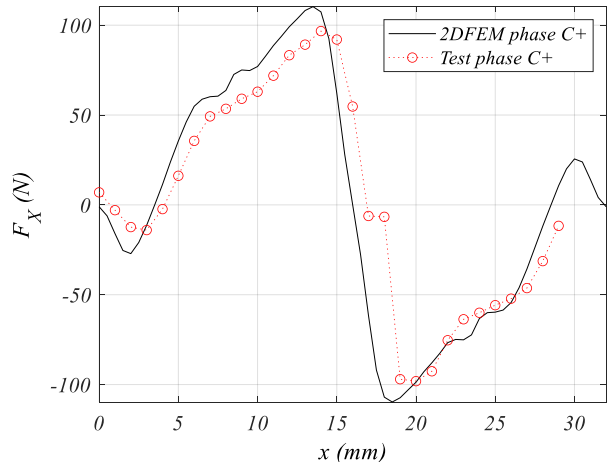

(b)

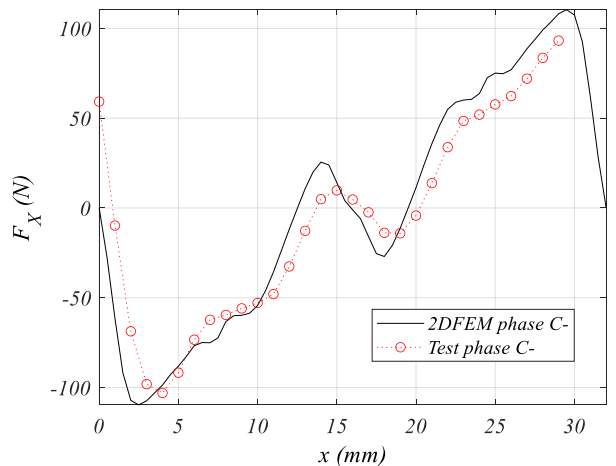

(d)

Figure 13. Propulsion force comparison results for $\mathrm{J}=10 \mathrm{~A} / \mathrm{mm}^{2}$, shift $=0 \mathrm{~mm}(\mathbf{a})$. Phase $\mathrm{I}_{\mathrm{B}}=3.12 \mathrm{~A}$. (b) Phase $\mathrm{I}_{\mathrm{C}}=3.12 \mathrm{~A}$. (c) Phase $\mathrm{I}_{\mathrm{B}}=-3.12 \mathrm{~A}$. (d) Phase $\mathrm{I}_{\mathrm{C}}=-3.12 \mathrm{~A}$.

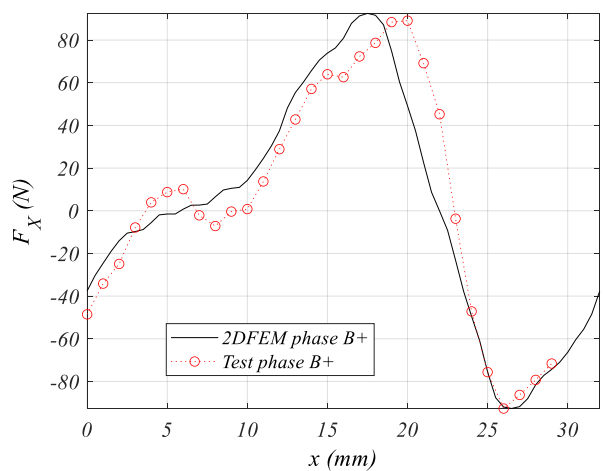

(a)

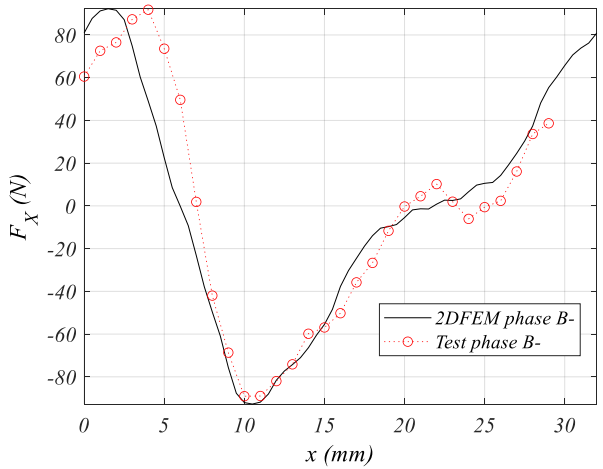

(c)

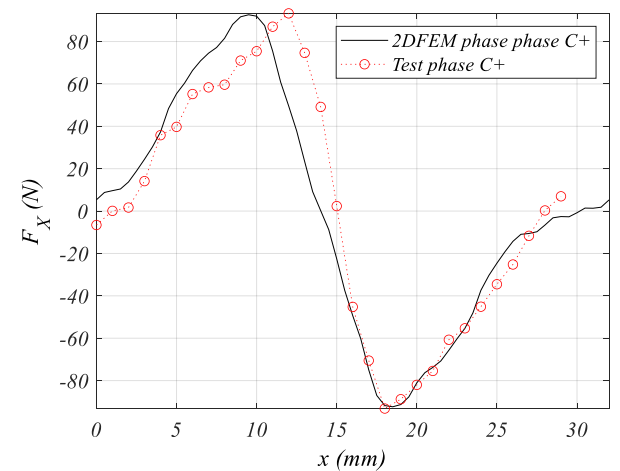

(b)

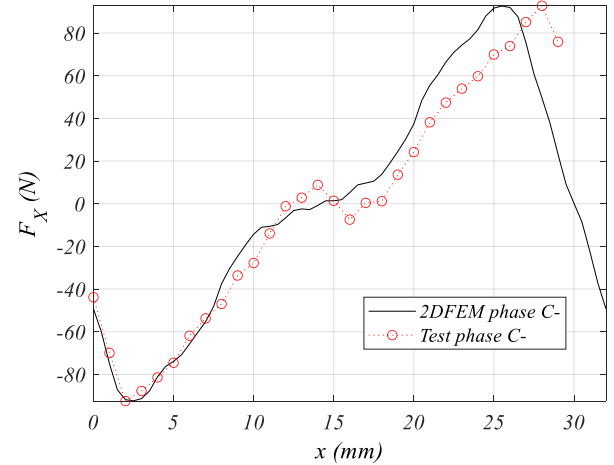

(d)

Figure 14. Propulsion force comparison results for $\mathrm{J}=10 \mathrm{~A} / \mathrm{mm}^{2}$, shift $=4 \mathrm{~mm}(\mathbf{a})$. Phase $\mathrm{I}_{\mathrm{B}}=3.12 \mathrm{~A}$. (b) Phase $\mathrm{I}_{\mathrm{C}}=3.12 \mathrm{~A}$. (c) Phase $\mathrm{I}_{\mathrm{B}}=-3.12 \mathrm{~A}$. (d) Phase $\mathrm{I}_{\mathrm{C}}=-3.12 \mathrm{~A}$. 


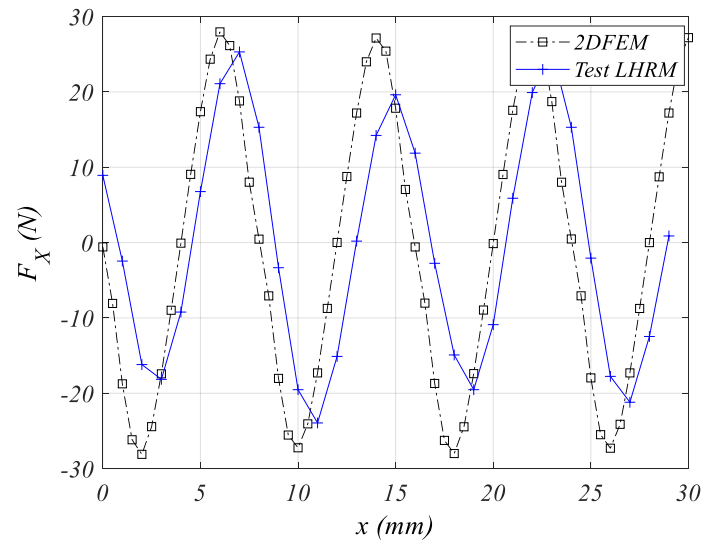

(a)

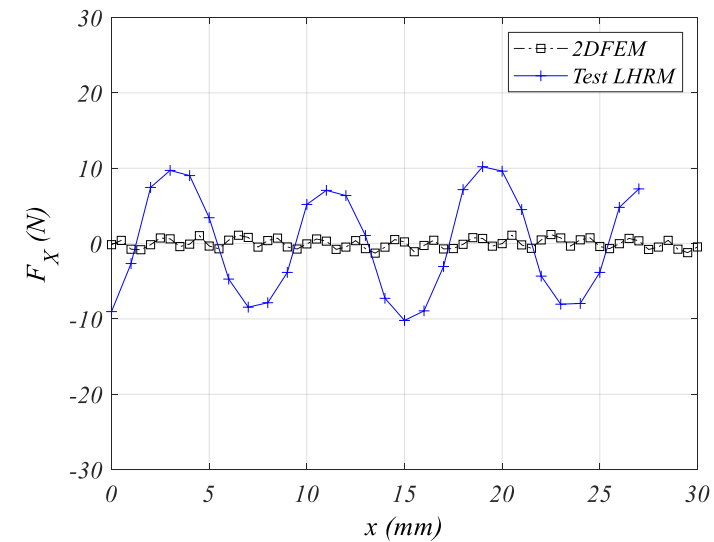

(b)

Figure 15. 2DFEM vs. experimental detent force comparison results. (a) $s=0 \mathrm{~mm}$. (b) $s=4 \mathrm{~mm}$.

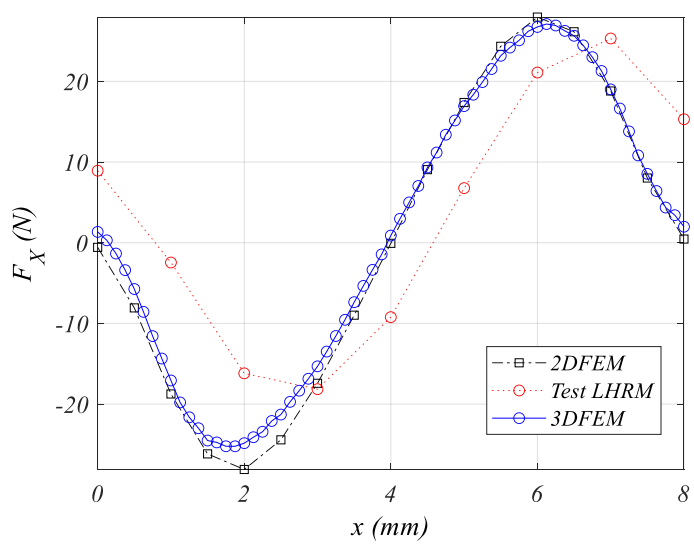

(a)

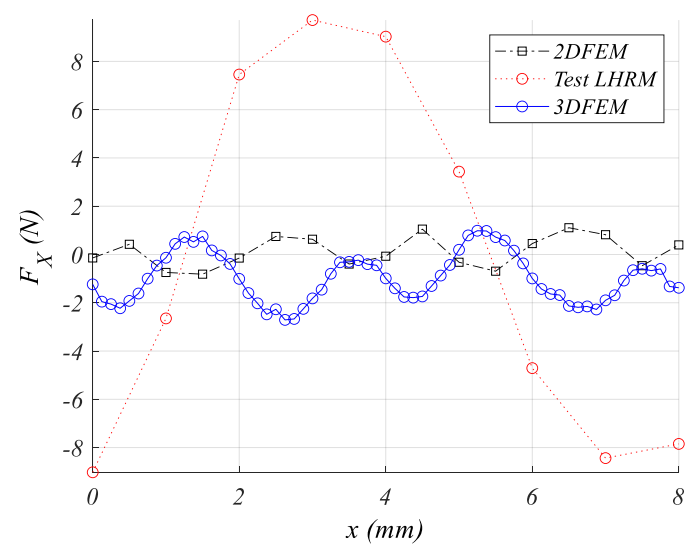

(b)

Figure 16. Detent force comparison results. (a) $s=0 \mathrm{~mm}$. (b) $s=4 \mathrm{~mm}$.

Such deviation in detent force for $s=4 \mathrm{~mm}$ can be due to the combination of three main causes. The first one is due to static friction, which is not accounted for in FEM simulations. The second cause is due to the mechanical assembly tolerances of the prototype. This affects two crucial aspects: (a) different airgap lengths due to constructive defects, and (b) the lower stator shift tolerance. A FEM sensitivity analysis has been carried out for the airgap tolerances (lengths), that is, the upper airgap $g_{1}=0.5 \pm \Delta g$, the lower airgap $g_{2}=0.5 \pm \Delta g$, and by taking a tolerance range of $\Delta g \in[-0.4,0.4]$ $\mathrm{mm}$. The curve patterns of detent force obtained from sensitivity analysis fit with the experimental measurement detent force pattern when $g_{1} \neq g_{2}$ (see Figure $15 \mathrm{~b}$ blue line), which indicates the probable existence of this kind of asymmetry, since only for $g_{1}=g_{2}$ the detent force is minimum $(s=4 \mathrm{~mm})$ and follows the pattern shown in Figure 8 (black line). The influence of the tolerance of the shift of lower semi stator can be seen in Figure 8. For instance, for $s=3 \mathrm{~mm}$ (see Figure 8) the detent force pattern matches the experimental detent force (see Figure 15b). These two observations, different airgap lengths and shift tolerances, lead to the conclusion of the existence of some mechanical asymmetry, not easy to quantify, which affects these highly sensitive parameters $\left(g_{1}, g_{2}, s\right)$ and produces this significant difference between FEM (2D and 3D) and experimental measures. The third cause of perturbation can be assigned to the end-effects phenomena, which produces a magnetic force at the stator edges $[38,41]$.

Despite this deviation in the experimental and FEM results, it is important to point out the relevant reduction $(>50 \%)$ in the detent force when one stator is shifted from $s=0$ to $s=4 \mathrm{~mm}$ (see Figure 15), which validates the methodology and the PM-LHRM as an interesting choice in high-density force applications. 


\section{Conclusions}

In this paper, a novel type of two-phase hybrid reluctance actuator (PM-LHRM) is presented. The stator is double-sided and consists of four laminated $U$ cores, two of them are placed on the upper side and the two others on the lower side. The permanent magnets are placed into the mover between their poles and have been disposed of with a determined magnetization. Each phase is energized by its $\mathrm{H}$-bridge to allow the switching of the phase current to a positive value $(+\mathrm{I})$ and to a negative value $(-I)$ in the period of conduction of each phase. The $U$ cores of the lower stator are shifted in respect to the $U$ cores of the upper stator for reducing the detent force. Simulations demonstrate that this actuator doubles the total thrust of an LSRM actuator of the same size, with a reduced detent force. The PM-LHRM was compared with a PM-LM (no poles in the mover), resulting in a lower detent force for $s=4 \mathrm{~mm}$ in the PM-LHRM structure and a higher peak and average force, $19 \%$ and $3.8 \%$, respectively.

From the results obtained, it can be drawn that the PM-LHRM structure has a better performance since applying a convenient force control (i.e., feeding with an appropriate current waveform), the force the ripple factor can be minimized, and the average propulsion force fit to its maximum value. It has also been revealed that the detent force of this actuator is highly sensitive to constructive defects, especially the airgaps length and the stator shift displacement.

Author Contributions: Conceptualization, J.G.-A.; methodology, J.G.-A. and P.A.; software, J.G.-A. and E.M.-P.; validation, J.G.-A., E.M.-P. and M.M.-G.; formal analysis, J.G.-A. and P.A.; investigation, J.G.-A.; resources, J.G.-A. and P.A.; data curation, M.M.-G.; writing-original draft preparation, M.M.-G.; writing-review and editing, J.G.-A. and P.A.; supervision, J.G.-A. All authors have read and agreed to the published version of the manuscript.

Funding: This research received no external funding.

Acknowledgments: To the collaboration of the company ARSAN-ESTAMPACIONES (Huarte-Pamplona, Spain).

Conflicts of Interest: The authors declare no conflict of interest.

\section{Nomenclature}

$b_{p} \quad$ Stator pole width $(\mathrm{m})$

$b_{s} \quad$ Mover pole width (m)

$c_{m} \quad$ Permanent magnet width (m)

$c_{p} \quad$ Stator slot width (m)

$c_{S} \quad$ Mover slot width (m)

$F_{x} \quad$ Propulsion force or thrust (N)

$F_{d} \quad$ Detent force (N)

$g \quad$ Air gap length (m)

$H_{c} \quad$ Permanent magnet coercivity $(\mathrm{kA} / \mathrm{m})$

$h_{y} \quad$ Stator yoke height (m)

$l_{m} \quad$ Permanent magnet length (m)

$l_{p} \quad$ Stator pole length $(\mathrm{m})$

$l_{s} \quad$ Mover pole length $(\mathrm{m})$

$m$ Number of phases

$N_{p h}$ Number of coils per phase

$\psi \quad$ Flux linkage $(\mathrm{Wb})$

$s \quad$ Shift $(\mathrm{m})$

$\tau \quad$ Period of detent torque $(\mathrm{m})$

$x \quad$ Mover position (m)

\section{Appendix A}

The number of wires per pole are 38, the wire diameter is $1.4 \mathrm{~mm}$, the number of coils per phase are four, and the material type of linear machine is specific magnetic steel type: M 270-50A, finally, the permanent magnets (PM) used in the linear switched machine are of neodymium material type, with specific denomination NdFeB-32. 


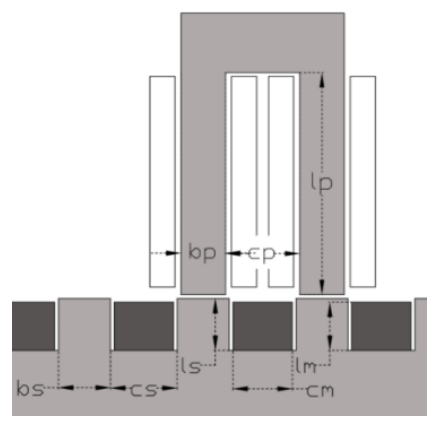

Figure A1. PM-LHRM main dimensions.

Table A1. PM-LHRM main dimension values.

\begin{tabular}{ccc}
\hline Mover pole width & $b_{s}$ & $7 \mathrm{~mm}$ \\
\hline Mover slot width & $c_{s}$ & $9 \mathrm{~mm}$ \\
\hline Mover slot height & $l_{s}$ & $7 \mathrm{~mm}$ \\
\hline Permanent magnet length & $l_{m}$ & $6.5 \mathrm{~mm}$ \\
\hline Permanent magnet width & $c_{m}$ & $8.5 \mathrm{~mm}$ \\
\hline Stator pole width & $b_{p}$ & $6 \mathrm{~mm}$ \\
\hline Stator slot width & $c_{p}$ & $10 \mathrm{~mm}$ \\
\hline Stator pole length & $l_{p}$ & $30 \mathrm{~mm}$ \\
\hline Number of wires per pole & $N$ & 38 \\
\hline Wire diameter & $d$ & $1.4 \mathrm{~mm}$ \\
\hline Number of coils per phase & $N_{p h}$ & 4 \\
\hline Magnetic steel & \multicolumn{3}{c}{ M 270-50A } \\
\hline Permanent magnet & \multicolumn{3}{c}{ NdFeB-32 } \\
\hline \multicolumn{3}{c}{}
\end{tabular}

\section{References}

1. Amoros, J.G.; Andrada, P. Sensitivity Analysis of Geometrical Parameters on a Double-Sided Linear Switched Reluctance Motor. IEEE Trans. Ind. Electron. 2010, 57, 311-319.

2. García, A.J.; Andrada, P.; Blanque, B.; Marin-Genesca, M. Influence of Design Parameters in the Optimization of Linear Switched Reluctance Motor under Thermal Constraints. IEEE Trans. Ind. Electron. 2018, 65, 1875-1883.

3. Szabó, L.; Viorel, I.A. On a high force modular surface motor. In Proceedings of the 10th International Power Electronics and Motion Control Conference (EPE-PEMC), Dubrovnik, Croatia, 9-11 September 2002.

4. Lim, K.C.; Woo, J.K.; Kang, G.H.; Hong, J.P.; Kim, G.T. Detent Force Minimization Techniques in Permanent Magnet Linear Synchronous Motors. IEEE Trans. Magn. 2002, 38, 1157-1160. [CrossRef]

5. Jang, S.; Lee, S.; Yoon, I. Design Criteria for Detent Force Reduction of Permanent-Magnet Linear Synchronous Motors with Halbach Array. IEEE Trans. Magn. 2002, 38, 3261-3263. [CrossRef]

6. Sung, W.S.; Gang, H.J.; Min, M.K.; Jang, Y.C. Characteristic Analysis of the Influence of Auxiliary Teeth and Notching on the Reduction of the Detent Force of a Permanent Magnet Linear Synchronous Machine. IEEE Trans. Appl. Supercond. 2018, 28, 1-5. [CrossRef]

7. Bascetta, L.; Rocco, P.; Magnani, G. Force Ripple Compensation in Linear Motors Based on Closed-Loop Position-Dependent Identification. IEEE/ASME Trans. Mechatron. 2010, 15, 3. [CrossRef]

8. Yu-Wu, Z.; Yun-Huyn, C. Thrust Ripples Suppression of Permanent Magnet Linear Synchronous Motor. IEEE Trans. Magn. 2007, 43, 2537-2539. [CrossRef]

9. Nevaranta, N.; Huikuri, M.; Niemelä, M.; Pyrhönen, J. Cogging force compensation of a discontinuous permanent magnet track linear motor drive. In Proceedings of the European Conference on Power Electronics and Applications (EPE'17 ECCE Europe), Warsaw, Poland, 11-14 September 2017. [CrossRef] 
10. Wang, Q.; Zhao, B.; Zou, J.; Li, Y. Minimization of Cogging Force in Fractional-Slot Permanent Magnet Linear Motors with Double-Layer Concentrated Windings. Energies 2016, 9, 918. [CrossRef]

11. Wang, M.; Li, L.; Pan, D. Detent Force Compensation for PMLSM Systems Based on Structural Design and Control Method Combination. IEEE Trans. Ind. Electron. 2015, 62, 11. [CrossRef]

12. Bianchi, N.; Bolognani, S.; Cappello, A.D.F. Reduction of cogging force in PM linear motors by pole-shifting. IEEE Proc. Electr. Power Appl. 2005, 152, 703-709. [CrossRef]

13. Kwon, Y.; Kim, W. Steady-State Modeling and Analysis of a Double-Sided Interior Permanent-Magnet Flat Linear Brushless Motor with Slot-Phase Shift and Alternate Teeth Windings. IEEE Trans. Magn. 2016, 52, 11. [CrossRef]

14. Setiabudy, R.; Herlina; Putra, Y.S. Reduction of cogging torque on brushless direct current motor with segmentation of magnet permanent. In Proceedings of the International Conference on Information Technology, Computer, and Electrical Engineering (ICITACEE), Semarang, Indonesia, 18-19 October 2017; pp. 81-86. [CrossRef]

15. Lim, H.S.; Krishnan, R.; Lobo, N.S. Design and control of a linear propulsion system for an elevator using linear switched reluctance motors. IEEE Trans. Ind. Electron. 2005, 55, 1584-1591.

16. Bae, H.-K.; Lee, B.-S.; Vijayraghavan, P.; Krishnan, R. A linear switched reluctance motor: Converter and control. IEEE Trans. Ind. Appl. 2000, 36, 1351-1359.

17. Lee, S.; Kim, S.; Saha, S.; Zhu, Y.; Cho, Y. Optimal Structure Design for Minimizing Detent Force of PMLSM for a Ropeless Elevator. IEEE Trans. Magn. 2014, 50, 1-4. [CrossRef]

18. Jahns, T.M.; Soong, W.L. Pulsating torque minimization techniques for permanent magnet AC motor drives-A review. IEEE Trans. Ind. Electron. 1996, 43, 321-330. [CrossRef]

19. Andrada, P.; Blanque, B.; Martinez, E.; Perat, J.I.; Sanchez, J.A.; Torrent, M. Environmental and life cycle cost analysis of one switched reluctance motor drive and two inverter-fed induction motor drives. IET Electr. Power Appl. 2012, 6, 390-398. [CrossRef]

20. Chen, H.; Nie, R.; Yan, W.A. Novel Structure Single-Phase Tubular Switched Reluctance Linear Motor. IEEE Trans. Magn. 2017, 53, 1-4. [CrossRef]

21. Zhao, W.; Zheng, J.; Wang, J.; Liu, G.; Zhao, J.; Fang, Z. Design and Analysis of a Linear Permanent- Magnet Vernier Machine with Improved Force Density. IEEE Trans. Ind. Electr. 2016, 63, 2072-2082. [CrossRef]

22. Enrici, P.; Dumas, F.; Ziegler, N.; Matt, D. Design of a High-Performance Multi-Air Gap Linear Actuator for Aeronautical Applications. IEEE Trans. Energy Convers. 2016, 31, 896-905. [CrossRef]

23. Pan, J.F.; Wang, W.; Zhang, B.; Cheng, E.; Yuan, J.; Qiu, L.; Wu, X. Complimentary Force Allocation Control for a Dual-Mover Linear Switched Reluctance Machine. Energies 2018, 11, 23. [CrossRef]

24. Andrada, P.; Blanqué, B.; Martínez, E.; Torrent, M.; Garcia-Amorós, J.; Perat, J.I. New Linear Hybrid Reluctance Actuator. In Proceedings of the International Conference on Electrical Machines (ICEM), Berlin, Germany, 1-4 September 2014.

25. Andrada, P.; Blanque, B.; Martinez, E.; Torrent, M. A Novel Type of Hybrid Reluctance Motor Drive. IEEE Trans. Ind. Electr. 2014, 61, 4337-4345. [CrossRef]

26. Ullah, S.; McDonald, S.; Martin, R.; Atkinson, G.J. A Permanent Magnet Assisted Switched Reluctance Machine for More Electric Aircraft. In Proceedings of the International Conference on Electrical Machines (ICEM), Lausanne, Switzerland, 4-7 September 2016.

27. Hwang, H.; Hur, J.; Lee, C. Novel permanent-magnet-assisted switched reluctance motor (I): Concept, design, and analysis. In Proceedings of the International Conference on Electrical Machines and Systems (ICEMS), Busan, Korea, 23-29 October 2013.

28. Lobo, N.S.; Lim, H.S.; Krishnan, R. Comparison of Linear Switched Reluctance Machines for Vertical Propulsion Application: Analysis, Design, and Experimental Correlation. IEEE Trans. Ind. Appl. 2008, 44, 1134-1142. [CrossRef]

29. Lin, J.; Cheng, K.W.E.; Zhang, Z.; Cheung, N.C.; Xue, X. Adaptive sliding mode technique-based electromagnetic suspension system with linear switched reluctance actuator. IET Electr. Power Appl. 2015, 9, 50-59. [CrossRef]

30. Chen, Y.; Cao, M.; Ma, C.; Feng, Z. Design and Research of Double-Sided Linear Switched Reluctance Generator for Wave Energy Conversion. Appl. Sci. 2018, 8, 1700. [CrossRef]

31. Hor, P.J.; Zhu, Z.Q.; Howe, D.; Rees-Jones, J. Minimization of cogging force in a linear permanent magnet motor. IEEE Trans. Magn. 1998, 34, 3544-3547. [CrossRef] 
32. Zhu, Z.Q.; Hor, P.J.; Howe, D.; Rees-Jones, J. Calculation of cogging force in novel slotted linear tubular brushless permanent magnet motor. IEEE Trans. Magn. 1997, 33, 4098-4100. [CrossRef]

33. Jung, S.Y.; Jung, H.K. Reduction of force ripples in permanent magnet linear synchronous motor. In Proceedings of the International Conference on Electric Machines (ICEM), Bruges, Belgium, 26 August 2002.

34. Kang, G.-H.; Hong, J.-P.; Kim, G.-T. A novel design of an air-core type permanent magnet linear brushless motor by space harmonics field analysis. IEEE Trans. Magn. 2001, 37, 3732-3736. [CrossRef]

35. Fujii, N.; Okinaga, K. X-Y linear synchronous motors without force ripple and core loss for precision two-dimensional drives. IEEE Trans. Magn. 2002, 38, 3273-3275. [CrossRef]

36. Liu, X.; Gao, J.; Huang, S.; Lu, K. Magnetic Field and Thrust Analysis of the U-Channel Air-Core Permanent Magnet Linear Synchronous Motor. IEEE Trans. Magn. 2017, 53, 1-4. [CrossRef]

37. Garcia-Amorós, J. Linear hybrid reluctance motor with high-density force. Energies 2018, 11, 2805. [CrossRef]

38. Inoue, M.; Sato, K. An approach to a suitable stator length for minimizing the detent force of permanent magnet linear synchronous motors. IEEE Trans. Magn. 2000, 36, 1890-1893. [CrossRef]

39. Meeker, D.C. Finite Element Method Magnetics, Version 4.2 (28 February 2018 Build). Available online: http://www.femm.info (accessed on 16 October 2018).

40. Altair Flux 3D. Altair 2019. Available online: http://www.altair.com/flux (accessed on 1 October 2020).

41. Zhu, Y.; Lee, S.; Chung, K.; Cho, Y. Investigation of Auxiliary Poles Design Criteria on Reduction of End Effect of Detent Force for PMLSM. IEEE Trans. Magn. 2009, 45, 2863-2866. [CrossRef]

(C) 2020 by the authors. Licensee MDPI, Basel, Switzerland. This article is an open access article distributed under the terms and conditions of the Creative Commons Attribution (CC BY) license (http://creativecommons.org/licenses/by/4.0/). 